\title{
Evaluating the quality of in-service trainings for employees of Islamic Azad University (Buin- Zahra Branch) using CIPP model
}

\author{
Aboulfazl Safieepoor ${ }^{a^{*}}$, Reza Shafizadeh ${ }^{a}$ and Behzad Shoghi ${ }^{\mathrm{b}}$
}

${ }^{a}$ Department of Human Science, Saveh Branch, Islamic Azad University, Saveh, Iran

${ }^{b}$ Young Researchers Club, Saveh Branch, Islamic Azad University, Saveh, Iran

\section{CHRON I C L E}

Article history:

Received June 22, 2013

Received in revised format

28 August 2013

Accepted 15 September 2013

Available online

September 172013

Keywords:

CIPP Model

Evaluation

Higher Education

In-service training

Quality of Training

\section{Introduction}

The world entered into the new millennium while the key of the societies to survive and to develop has been found in human resources and in developing the centers, which deal with the nurturing of the human forces. Undoubtedly, the success of such centers depends on dynamism and flexibility of human resources. To reach this goal, we need to pay more attention on in-service trainings of the employees as one of the most efficient solutions in the organizations. Generally speaking, fulfilling the organizational objectives requires the improvement of the capabilities and skills, which are

\footnotetext{
*Corresponding author.

E-mail address: asp562002@yahoo.com (A. Safieepoor)

(C) 2013 Growing Science Ltd. All rights reserved. doi: $10.5267 /$ j.ms 1.2013 .09 .021
} 
necessary for performing the assigned tasks and playing the assigned roles, and furthermore, the employees have to be trained constantly (Mastaneh \& Ganjeali, 2007).

Meanwhile, universities are especial kind of organizations, which deal with diverse human resources. Universities are considered as valuable institution where the society needs to be developed. The universities preserve and transfer the cultural heritage and values of the society and are held responsible for the requirements of the society to acquire, promote, and develop the knowledge and technology (Fitzpatrick, 2004). Teaching and university issues play essential role in this process and thus they require being coordinated with other changes and developments of the world (Eichenwald, 1998). This is while the dynamism of the human societies, rapid technological achievements, and the effect of such changes on university employees have caused the education can be changed along with other changes of the world. These issues have made the prediction and planning the changes in the universities seem necessary (Mortezai, 2002).

In-service training courses have become popular method to improve scientific growth of organizations. However, one of the most important concerns of the organizations is the quality of inservice training courses of the employees of such organizations (Akbari, 2009). Generally speaking, in-service training includes the knowledge, the skills, and the abilities presented for the employees at work. Therefore, the primary objective of in-service trainings is to improve the performance, to update the information, to promote the jobs, to handle the problems, to prepare employees for promotion, and to familiar them with the organizational goals (Jarvis, 2004).

Quality is one of the most important concerns in the higher education systems. The success of the universities and higher education institutes in achieving the educational goals and expectation depends on paying more attention to the improvement of the quality of training courses. Quality in higher education can be described as the accommodation between the current situation of each of the factors of educational factors such as the context, input, process, and product with the standards, aims and expectations of the education. This is fulfilled through the establishment of an efficient system for educational evaluation in each of the university systems (Yarmohammadian, 2004, Mohammad Zadeh, 2003). Evaluation is a tool that can change the education from a static process to a dynamic one (Falahati, 2002). Proper and systematic assessment can reinforce the strengths and correct the weaknesses. Additionally, such an evaluation can be a basis for many decision-makings and educational programming and thus it could lead to the promotion of the scientific level of the university (Akbari, 2009). Evaluation of the higher education is a tool implemented for the fulfillment of the higher educational goals (Aitkin, 1991). Considering the experts' expectations of the results of assessment, there are various viewpoints about the nature of the evaluation. These differences have led to various techniques and methods on the educational evaluation so that the concept of the evaluation would change the judgment about the values or competencies of the educational phenomena (Stufflebeam, 2000).

Among the available models in the evaluation of the higher educational systems, CIPP evaluative model is a model that is one of the popular methods. CIPP is an abbreviation in which the letter "C" stands for context, "I" stands for input, "P" stands for process, and "P" stands for product because this model of the evaluation is indeed a framework, which allows the managers and decision-maker to take appropriate actions in four types of decisions (Seif, 2011). The primary reason for frequent usage is that the CIPP model was comprehensive framework where one can obtain needed information about the desirability of the university development goals, desirability of the operational plans. In addition, the desirability of the results of the university development plans in order to conduct and to decide on the improvement of the university activities and obtaining the feedback on that university (ibid).

Seif (2011) stated that CIPP evaluation model could be adopted from the management-based evaluation model whose primary objective is to help the managers and decision-makers. This model 
emphasizes on the systemic approach in which the decisions about the inputs, processes, and outputs are built, and the authorities and decision-makers determine the desirability of the programs (ibid). CIPP deals with the concepts that root in the goals, tests, and experimental plans. The planners of this model believe that CIPP model depends on four dimensions of context, input, process and product in a systemic approach to evaluate the "target system" and finally facilitate the decision-making (Bazargan, 2005; Shams, et al, 2008).

RigiGolabi and Yaghoubi (2010) evaluated the educational effectiveness of the occupational program based on CIPP model in Iran and reported that all four hypotheses on the evaluation of context, input, process and product were confirmed. Their results indicated that the training courses were effective at a relatively desirable level. Moreover, they reported that the training courses for the managers and deputies of Khuzestan Steel Company were in desirable level. Akhlaghi, et al. (2011) evaluated the quality of training courses in higher education based on CIPP model and found that the highest level of overall desirability belongs to the factor of academic boards (4.84) in the field of input (section of human resources), and the lowest level of the overall desirability belongs to the factor of budget (2.50) in the field of input (section of financial resources. They explained that continuous evaluation of the departments of Medical Documents and MSC of Medical Documents could help them find the weaknesses and strengths of the programs and promote the level of their quality.

\subsection{Islamic Azad University of Buin Zahra}

Buin Zahra branch of Islamic Azad University was founded in 2003 and presently has 2 faculties, 78 employees, and 47 academic members and it is an active in education at associate, bachelor, and master levels. One of the issues, which make the researches interested in this research is that it did have any mechanism for comprehensive evaluation of this unit. In fact, despite several years of activities in the in-service training activities for its employees, in-service trainings in Buin Zahra university has been unilateral. Therefore, it seems necessary to do a systematic evaluation and define an evaluation system with high executive guarantee. This is why this research looks for evaluating the quality of in-service trainings of the employees of Buin Zahra branch of Islamic Azad University based on CIPP model.

\subsection{Hypotheses of the survey}

The hypotheses and conceptual model of this research are as follow:

Main hypothesis: In-service trainings of the employees of Buin Zahra branch of Islamic Azad University are in desirable quality.

Subsidiary hypothesis 1: The dimension of context in the in-service trainings of the employees of Buin Zahra branch of Islamic Azad University is in desirable quality.

Subsidiary hypothesis 2: The dimension of input in the in-service trainings of the employees of Buin Zahra branch of Islamic Azad University is in desirable quality.

Subsidiary hypothesis 3: The dimension of process in the in-service trainings of the employees of Buin Zahra branch of Islamic Azad University is in desirable quality.

Subsidiary hypothesis 4: The dimension of product in the in-service trainings of the employees of Buin Zahra branch of Islamic Azad University is in desirable quality.

Subsidiary hypothesis 5: There is a significant relationship between the different dimensions of quality evaluation of the in-service trainings of the employees of Buin Zahra branch of Islamic Azad University. 


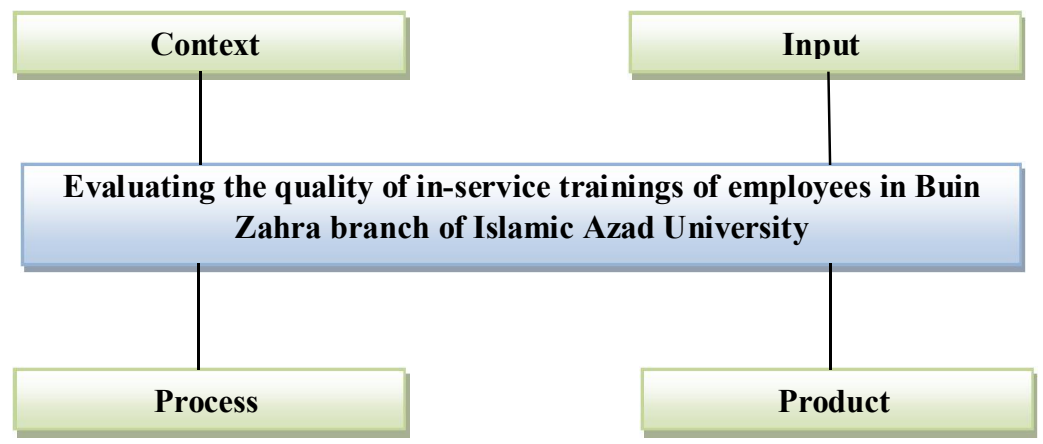

\section{Methodology}

Fig. 1. Conceptual model of the research (author-designed)

The methodology of this research is functional according to the nature of its subject and its objective; it is descriptive with regard to its nature; and it is a correlative survey according to its data collection method because it has polled the opinions of the involved subjects to confirm its hypotheses. Moreover, this is a quantitative research with regard to the type of its collected data. Accordingly, we planned and distributed a series of questionnaires in order to collect the opinions of the employees of Buin Zahra branch of Islamic Azad University in 2013. Then we analyzed the collected data using descriptive statistics (including frequency, percent frequency, mean, standard deviation, and range of variations), and inferential statistics (including one-sample T-test, exploratory factor analysis, confirmatory factor analysis, and structural equation model).

\subsection{Statistical population, sampling method, and sample size}

Statistical population of the research includes all employees who participated in in-service trainings from 2003 to 2012. Since all the statistical population of the research has been studied through the census, thus no sampling was needed to be performed. Considering all in-service courses that have been conducted from 2003 to 2012 in Buin Zahra branch of Islamic Azad University, all employees attended in the courses including 78 employees of the university and thus the statistical population of the research included 78 employees of the subjected university.

\subsection{Data collection instrument}

The main instrument of this research is a Likert-based questionnaire based on a checklist originally introduced by Stufflebeam in 2000 for evaluating the training courses based on CIPP model. This questionnaire maintains four fields including context, input, process, and product and contains 53 questions, which are completed by the employees who had passed in-service courses. Table 1 shows the evaluative dimensions of the training courses.

Table 1

Dimensions and questions of the questionnaire

\begin{tabular}{ccc}
\hline Dimensions & Number of questions & Relevant questions in the questionnaire \\
\hline Context & 7 & $1-7$ \\
Input & 17 & $8-24$ \\
Process & 9 & $25-33$ \\
Product & 20 & $34-53$ \\
\hline
\end{tabular}

\subsection{Validity and reliability of the questionnaire}

The measuring instrument of the research must be able to analyze the information and data of the research and so, the mentioned instrument has to be valid and reliable.

Validity: in order to determine the validity of the questionnaire of this research we relied on the opinions of the experts of the field and applied their corrective comments on the questionnaire. It is to 
be mentioned that the validity of the questionnaires had been confirmed in previous researches that had been conducted in the literature. Moreover, in order to investigate the construct validity of the research we used structural equation model and Smart PLS software. Construct validity is divided into two sections: convergent validity and divergent validity. In order to determine the convergent validity of the research we used Average Variance Extracted (AVE) criterion whose results for the variables of the research is shown in table 2 .

Table 2

Convergent validity of the questionnaire

\begin{tabular}{lcccc}
\hline Dimensions & Context & Input & Process & Product \\
AVE & 0.625 & 0.636 & 0.598 & 0.711 \\
\hline
\end{tabular}

The criterion value for the acceptance level of AVE is 0.5 (Hulland, 1999). According to the results of Table 2, all AVE values for the constructs are higher than 0.5 and these values confirm the convergent validity of the research questionnaire at an acceptable level. On the other hand, in divergent validity, the difference between the items of a construct has been compared to the items of other constructs of the model (DeVellis, 2003). To do this, the square root of the AVE in each construct is being calculated against the values of the correlation coefficient between the constructs. In this regard, we will need a matrix that includes the matrix main diagonal of the AVE coefficient of each construct, and the values of the upper and lower of the main diagonal includes the correlation coefficient between each construct and the other constructs. This matrix is shown in table 3. As it can be seen in Table 3, the square root of AVE for any construct is higher than the correlation coefficient of that construct with the others, which confirms the divergent validity of the constructs.

\section{Table 3}

Divergent validity of the questionnaire

\begin{tabular}{lcccc}
\hline Dimensions & Context & Input & Process & Product \\
\hline Context & 0.791 & & & \\
Input & 0.154 & 0.798 & & \\
Process & 0.312 & 0.335 & 0.773 & 0.843 \\
Product & 0.219 & 0.201 & 0.203 & \\
\hline
\end{tabular}

Reliability: in this research, in order to determine the reliability of the questionnaire we used Cronbach's alpha method and structural equation modeling method. In this regard, first, we calculated the Cronbach's alpha coefficient of the dimensions of the questionnaire using SPSS 20 software. As shown in Table 4, all coefficient values are higher than 0.7 and thus the questionnaire of the research is reliable. Moreover, the coefficient of the composite reliability (CR) is being used to assess the reliability of the questionnaires. The relevant $\mathrm{CR}$ values for each dimension of the research have been calculated and are shown in Table 4. According to Hulland (1999) if the values of composite coefficients are higher than 0.7, then the relevant questionnaire will be sufficiently reliable. Accordingly, we can claim that our research instrument has been reliable.

Table 4

Reliability of the questionnaire

\begin{tabular}{lcccc}
\hline Dimensions of the questionnaire & Context & Input & Process & Product \\
\hline Cronbach's alpha & 0.701 & 0.738 & 0.822 & 0.801 \\
Composite reliability (CR) & 0.782 & 0.791 & 0.856 & 0.834 \\
\hline
\end{tabular}

\section{Findings}

\subsection{Findings resulted from the demographical characteristics}

In this research, $61.6 \%$ of the participants were male and $38.4 \%$ of the participants were female. Educationally, the biggest sample group had a bachelor degree $(57.7 \%)$, while $37.2 \%$ of the 
participant had an associate degree or lower. This is while the employees with master degree or higher than master, were only $5.1 \%$ of the participants. The work experience of the subjects varied from 0 to 10 years; while $48.7 \%$ of the subjects had $0-3$ years of experience, $2.6 \%$ of the subjects had 3-6 years of experience, and remaining $48.7 \%$ of the subjects had $6-10$ years of experience.

3.2. Testing the subsidiary hypotheses 1 to 4: dimensions of context, input, process, and product in the in-service trainings of the employees of Buin Zahra branch of Islamic Azad University have a desirable quality.

In this research, we used one-sample T-test to determine whether the mean of the relevant data for the four main dimensions are equal to the mean of the supposed population $(=3)$. The results of the onesample T-test for the dimensions of context, input, process, and product are shown in table 5.

Table 5

Results of one-sample T-test for the dimensions of CIPP model

\begin{tabular}{lccccc}
\hline Dimension & t-value & Significance level & $\begin{array}{c}\text { Error } \\
\text { level }\end{array}$ & \multicolumn{2}{c}{$\begin{array}{c}\text { Difference distance at } \mu-3 \text { level } \\
\text { (95\% confidence level) } \\
\text { Lower bound }\end{array}$} \\
\hline Context & & & 0.05 & 0.35 & 0.44 \\
Input & 6.79 & 0.000 & 0.05 & 0.36 & 0.16 \\
Process & 7.11 & 0.001 & 0.05 & 0.62 & 0.45 \\
Product & 5.33 & 0.000 & 0.05 & 0.25 & 0.76 \\
\hline
\end{tabular}

Since the significance level of each of the dimensions is less than 0.05, thus the null hypothesis is rejected; that is, there is a significant difference between the dimensions of context, input, process, and product on one hand and the supposed population (3) on the other hand at the confidence distance of $95 \%$. The positive values of upper and lower bounds of difference between the mean of the dimension of context and the value of 3 show that the mean of scores for each dimension is higher than 3. In other words, the dimensions of context, input, process, and products of the in-service training courses are at a desirable level. Since all subsidiary hypotheses of the research were confirmed, we can conclude that the in-service trainings of the employees of Buin Zahra branch of Islamic Azad University have a desirable quality, and hence the main hypothesis of the research is confirmed as well.

3.3. Testing the subsidiary hypotheses 5: There is a significant relationship between the different dimensions of quality evaluation of the in-service trainings of the employees of Buin Zahra branch of Islamic Azad University.

In this section, we used the multiple variance analysis test (ANOVA) to determine the difference between four dimensions of CIPP model (i.e. context, input, process, and product) for evaluating the quality of in-service trainings of employees of Buin Zahra branch of Islamic Azad University. ANOVA test can determine whether the quality of training courses in these four dimensions is the same or not. The results of the ANOVA test are summarized in Table 6.

Table 6

Results of ANOVA for testing the $5^{\text {th }}$ subsidiary hypothesis

\begin{tabular}{cccc}
\hline & Significance level & Degree of freedom & F-statistic value \\
Context & 0.000 & 52 & 1.657 \\
\hline Input & 0.000 & 52 & 0.512 \\
Process & 0.000 & 52 & 0.556 \\
Product & 0.000 & 52 & 1.359 \\
\hline
\end{tabular}

Based on the results of Table 6 and the considering the significance level that is higher than 0.05 for all dimensions, we can conclude that there is a significant relationship between the different 
dimensions of quality evaluation of the in-service trainings of the employees of Buin Zahra branch of Islamic Azad University; and thus the fifth subsidiary hypothesis of the research is confirmed as well.

\section{Discussion and conclusion}

Evaluating different training courses of higher education is a necessary solution for improving the quality of educational courses of the universities. In this research, we have analyzed the data and tested each of the hypotheses, and consequently we came to some results. At the following section, we explained hypotheses. Based on main hypotheses we can conclude that Buin Zahra University has offered suitable in-service trainings for its employees to improve the level of its employees' skills at a desirable level. The results of testing the first subsidiary hypothesis on the dimension of context showed that this dimension maintained a desirable quality in the in-service training courses of the employees of Buin Zahra branch of Islamic Azad University. Accordingly, we can conclude that Buin Zahra University has managed to understand the problems, limitations, and difficulties of its own organization and has successfully analyzed its problems to offer needed trainings for solving the mentioned problems by its employees. The findings of our research that was based on the mean and one-sample T-test showed that the dimension of input has a desirable quality in the in-service training courses of the employees of Buin Zahra branch of Islamic Azad University. Thus considering the dimension of the input in the in-service training courses of the employees of Buin Zahra branch of Islamic Azad University, we can claim that the educational equipment and facilities for administering these courses for the employees and the teachers of these training courses have maintained a desirable quality. In addition, educational content and materials implemented in these in-service training courses have been desirable in the opinions of the employees.

The results of testing the third subsidiary hypothesis on the dimension of process showed that this dimension maintained a desirable quality in the in-service training courses of the employees of Buin Zahra branch of Islamic Azad University. Thus, we can conclude that the evaluation of the dimension of process is highly desirable according to the employees of Buin Zahra University; that is, this dimension has managed to meet its predetermined goals. Thus the learners of these in-service training courses believed that the classes have been flexible, the learners have good relationship with their trainers for solving their scientific problems, the courses have had a desirable order and discipline, and generally, the executive agents, learners, and their feedback have been coordinated and desirable. Considering the obtained mean for the questions of this dimension (3.50) we can conclude that like the previous dimensions, the output or product of these training courses for the employees of Buin Zahra branch of Islamic Azad University has a desirable quality. Among the strengths of this dimension we can point to the practicality of the learnt knowledge and skills with regard to the occupational needs of the learners and abilities of such courses in changing the attitudes of the learners about their works.

Finally, with regard to the results of previous hypotheses of the research we can state that there is a significant relationship between the different dimensions of quality evaluation of the in-service trainings of the employees of Buin Zahra branch of Islamic Azad University. Based on the results of ANOVA test, we observed that there is a significant relationship between the different dimensions of quality evaluation of the in-service trainings of the employees of Buin Zahra branch of Islamic Azad University. Finally, relying the results of the mean test we can state that the mean of the dimension of context (3.76) is higher than the mean of the other dimensions; so the quality of this dimension is more desirable than the quality of other dimensions. We may therefore suggest to create a secretariat of the training quality in organization that presents the different solutions in the field of the training quality and conducts various researches and studies to plan and operationalize the needed criteria for the quality control. It is recommended to change the location of the courses in various terms in order to encourage more participants to attend in the training workshops. In order to have a better coordination and to come to a more rapid development of the team workings, and consequently to 
obtain a better learning, we may classify the participants according to their field of study, their proficiency, and their specialized needs. It is also possible to increase the authority of the employees to offer the courses that they feel necessary to be participated.

\section{References}

Akbari, N. (2009). Evaluation methods in educational system. Green Journal, Professional Quarterly of education in medical sciences. Proceedings of the 10th National Education Conference in Medical Sciences, 15-16.

Akhlaqi, F., Yarmohammadian, M.H., Khoshgam, M. ,\& Mohebbi, N. (2001). Evaluating the quality of training courses in higher education based on the CIPP model. Health Information Management, 8, 621-629.

Aitkin, D. (1991). How research came to dominate higher education and what ought to be done about it. Oxford Review of Education, 17(3), 235-247.

Bazargan, A. (2001). Educational Evaluation (Concepts, Models, and Operational Process), Tehran: SAMT Publications [In Persian].

Bazargan, A. (2005). Inter-university evaluation and its application in the continuous improvement of the quality of higher education. Quarterly of the Research and Programming in Higher Education, 3(4), 61-74.

DeVellis, R. (2003). Scale development: Theory and applications, (2nd ed). Thousand Oaks, CA: Sage.

Eichenwald, S. (1997). Education: the key to HIM transformation. Journal of AHIMA/American Health Information Management Association, 69(7), 42-45.

Falahati A.R. (2002). Evaluation Programs of Educational groups in Dentistry Faculty [MSc Thesis]. Khorasgan Branch, Islamic Azad University.

Fitzpatrick, J.L. (2004). Worthen Sanders Program evaluation: alternative approaches and practical guidelines. $3^{\text {rd }}$ ed. Boston: Pearson/Allyn and Bacon.

Foroughi Abri, A.A, Nadi, M.A. \& Ebrahimpur, A. (2008). Effective factors on the improvement of the quality of in-service training courses for the employees of Islamic Azad Univerisity, Khorasegan Branch. Research in Educational Programming, 22, 61-78.

Hulland, J. (1999). Use of partial least squares (PLS) in strategic management research: a review of four recent studies. Strategic Management Journal, 20(2),195-204.

Kazemi, M. \& Hamrahi, M. (2009). Pathology of the in-service training courses based on the CIPP model (Case study: Iranian Fars Province). Management Studies, 4, 113-130.

Khorasani, A. \& Farahi, F. (2012). Evaluating the effectiveness of in-service training courses for employees of Khuzestan Steel Company based on CIPP model. $8^{\text {th }}$ Conference of the Human Resources Development, Tehran: Research Center of the Productivity and Human Resources.

Raoufi, M.H., \& Ghouchani, A. (2004). The Effectiveness of In-service Training on the Efficiency and Productivity of the Managers and Employees of the Schools. Educational and Psychological Researches, 5, 67-79.

Rigi Golabi, P. \& Yaghoubi, N.M. (2010). Evaluating the effectiveness of the Training the Occupational Program of Sistan and Baluchestan Governance based on CIPP model.

Seif, A. (2011). Measuring and Evaluating the Educational Progress, Tehran: Dowran Publication.

Shams B., Gholshiri, P., Zamani, A.R. \& Pourabdian, S. (2008). Mothers' participation in improving growth and nutrition of the children: A model for community participation. Iranian Journal of Publication Health., 37(2), 24-31.

Stufflebeam, D. L., (2000). The CIPP model for evaluation. In D. L. Stufflebeam, \& T. Kellaghan, (Eds.), The international handbook of educational evaluation. Boston: Kluwer Academic Publishers.

Stufflebeam, D.L. (2000). The metaevaluation imperative. American Journal of Evaluation, 22(2), 183-209.

Tazakkori, Z., Mazaheri, E., Torabi Zadeh, K., Fathi, S. \& Ebrahimi, F. (2010). Evaluating PhD courses of nursing in Iran; an application of CIPP model. Scientific Journal of Ardabil Faculty of Nursing, 12, 44-51.

Yarmohammadian, M. H. (2004). Quality in Higher Education. Encyclopedia of Higher Education. Tehran: Ministry of Science, Research, and Technology Publication.

Zandavian Naeini, A. (2006). Comprehensive evaluation of Khuzestan Teachers Training Centers based on CIPP model. Educational and Psychological Journal of Shahid Chamran University of Ahwaz, 2, 162-137 [in Persian]. 